\title{
Consumo e Formação dos Hábitos de Esporte e Lazer
}

Fernando Renato Cavichiolli* Fernando Marinho Mezzadri** Fernando Augusto Starepravo**

Resumo: O objetivo do texto é iniciar uma análise dos hábitos de esporte e lazer da população da cidade de Curitiba. Os dados foram coletados durante o projeto "Viva - Verão" do Governo do Estado do Paraná. O procedimento adotado para a obtenção dos dados foi a pesquisa exploratória, com o objetivo de proporcionar uma visão geral sobre o tema. Os dados coletados por meio da pesquisa exploratória constituem a primeira etapa de uma investigação mais ampla. Neste texto vamos nos restringir à faixa etária de 18 a 30 , que corresponde a um momento de transição entre a juventude e a vida adulta. A partir dos dados obtidos, analisamos as seguintes categorias: faixa etária, renda familiar, grau de escolaridade e como os indivíduos utilizam seu tempo livre. Consideramos também o estado civil, a paternidade, o grau de maturidade da família (se os filhos moram juntos ou separados dos pais) e o significado dos consumos de esporte e lazer. Para orientar a discussão de hábitos, tempo livre e consumo, utilizamos os seguintes referenciais teóricos: Veblen e os conceitos de consumo conspícuo, a escola de Frankfurt e o conceito de indústria cultural e, por último, Featherstone, que utiliza os conceitos configuracionistas e o consumo. Acreditamos que esse estudo poderá trazer subsídios para professores/pesquisadores e gestores públicos, pois possibilitará a compreensão mais aprofundada de algumas formas de comportamento do cidadão.

Palavras-chave: Atividades de lazer. Esportes. Política social.

Doutor em Educação, professor da Universidade Federal do Paraná, Departamento de Educação Física, Centro de Pesquisa em Esporte Lazer e Sociedade (CEPELS).

Doutor em Educação Física, professor da Universidade Federal do Paraná, Departamento de Educação Física, Centro de Pesquisa em Esporte Lazer e Sociedade (CEPELS) Mestre em Educação Física, professor da Faculdade Guairacá, Centro de Pesquisa em Esporte Lazer e Sociedade (CEPELS).

Movimento, Porto Alegre, v.12, n. 02, p. 241-271, maio/agosto de 2006. 


\section{Introdução}

Em janeiro de 2005, estabelecemos uma parceria entre a Universidade Federal do Paraná e a Paraná Esporte, autarquia responsável pelo planejamento e execução das políticas públicas no Paraná. Esta parceria propiciou o estudo exploratório sobre a aquisição dos hábitos de esporte e lazer. Posteriormente, apresentamos uma proposta de investigação, a Rede CEDES (Centro de Desenvolvimento do Esporte Recreativo e do Lazer), muito ampla e de longo prazo. Nos próximos anos, vamos coletar uma série de dados no sentido de proporcionar subsídios para o poder público no que se refere ao esporte e o lazer. A princípio a Rede CEDES está possibilitando a pesquisa na região metropolitana de Curitiba e na região do litoral, o que é bastante representativo em termos de concentração populacional.

A intenção é ampliar gradativamente as faixas etárias, assim como estender a pesquisa às diferentes regiões do Estado do Paraná. Outras cidades com mais de 100 mil habitantes, tais como Londrina, Maringá, Foz do Iguaçu, Cascavel e Ponta Grossa, serão alvos no futuro.

A proposta de estudo deriva de discussões sobre consumo e aquisição de hábitos de esporte e lazer dentro do Centro de Pesquisa em Esporte, Lazer e Sociedade (CEPELS), do Departamento de Educação Física da Universidade Federal do Paraná. Então decidimos que a primeira pesquisa de coleta de dados deveria ser exploratória. Assim, direcionamos a pesquisa de campo para a faixa etária cujo poder aquisitivo começa a se esboçar com maior força se comparada com o período anterior. É a faixa etária de 18 a 30 anos, que corresponde a um momento de transição entre a

${ }^{1}$ A pesquisa sobre hábitos de esporte e lazer da população paranaense está em andamento graças às parcerias com a Paraná Esporte - Departamento de Lazer e com o Governo Federal. Ministério do Esporte . Secretaria do Desenvolvimento do Esporte Amador e do Lazer.

Movimento, Porto Alegre, v.12, n. 02, p. 241-271, maio/agosto de 2006. 
juventude e a vida adulta. A posse do dinheiro e do poder de decisão se evidencia mais acentuadamente nessa fase, mas, em contrapartida, o tempo livre sofre uma queda considerável, assim como a subordinação ao mundo dos adultos. Aqui, as atividades consideradas rotineiras ganham força.

A investigação sobre a passagem da juventude para a vida adulta é de significativa importância para se compreender o sentido da formação de diferentes hábitos, no caso específico a formação de determinadas atitudes expressas no esporte e no lazer. É um erro se compreender esse momento como uma realidade homogênea, baseando-se no senso comum, e isso ocorre provavelmente porque numa análise geral o tempo livre caminhe numa perspectiva do mundo do trabalho.

Todavia, gostaríamos de verificar se nessa passagem há possibilidades de os adultos construírem suas normas próprias e modos de ser que não necessariamente estejam vinculados ao denominado mundo do trabalho, ou se as normas são constituídas com a lógica da racionalidade do mundo do trabalho. Se comparada com a fase anterior, na juventude os meios de controle social se evidenciam mais claramente. Entretanto, vamos verificar se não há resquícios de traços de subjetividades coletivas, liberdade de escolha e exercício de inserção efetiva nas relações sociais.

Enfim, o esporte e o lazer são simplesmente um adendo do mundo do trabalho ou podem ser considerados como espaços de aprendizagem das relações sociais num contexto de transição? Ou será que o tempo livre, que deveria ser entendido como sinônimo de liberdade de escolha e liberdade de experimentação, não estaria sendo gasto em lazer, mas sendo transformado em tempo de penúria, de falta de oportunidades e de opressão?

Teremos mais clareza sobre essas questões quando daqui a alguns anos oportunizarmos um quadro mais amplo, envolvendo diferentes faixas etárias. É importante destacar que os dados sobre a utilização do tempo livre por meio de atividade de esporte e

Movimento, Porto Alegre, v.12, n. 02, p. 241-271, maio/agosto de 2006. 
lazer, da população em geral, resultam num quadro de carência. As ações políticas são desenvolvidas por meio de atitudes voluntárias, sem uma base para que possam ajudar nas afirmações sobre aquilo que as pessoas podem e desejam realizar. O conhecimento sobre essa realidade cultural pode contribuir para planos de governos ou ações mais efetivas.

As pessoas analisadas neste texto nasceram entre 1975 e 1987, e em função do momento histórico em que passaram a existir estão fadadas a uma caminhada muito próxima se continuarem em Curitiba, e então é de se esperar que a maioria vivencie essa realidade em estágios semelhantes: terminarão juntos os estudos, irão procurar empregos na mesma época, frequientarão os mesmos clubes, praças e movimentos culturais juntas e provavelmente terão seus filhos na mesma época.

Este texto procura abrir a discussão sobre a aquisição de hábitos de esporte e lazer na Rede CEDES, por meio de alguns autores clássicos das ciências sociais - Veblen e a Escola de Frankfurt (especificamente Adorno e Horkheimer), assim como Featherstone, que utiliza os conceitos configuracionistas. Além desses autores, vamos apresentar o resultado parcial das entrevistas feitas com curitibanos durante o Projeto "Viva o Verão".

\section{Algumas leituras sobre consumo}

Com o livro intitulado A teoria da classe ociosa, Veblen (1974) tornou-se um clássico na literatura das ciências sociais. Nessa obra, o interesse central concentra-se nos temas ligados à estratificação e à mobilidade sociais e ao surgimento da classe ociosa, que se originou no interior das classes altas, marcadamente constituída por pessoas que não exerciam as atividades industriais. O que nos interessa aqui, primeiro, é a discriminação de ocupações, traço marcante para o surgimento da classe ociosa. A ocupação dessa classe apóia-se em quatro tipos de atividades: governamentais, guerreiras, religiosas e esportivas. Segundo, que a acumu-

Movimento, Porto Alegre, v.12, n. 02, p. 241-271, maio/agosto de 2006. 
lação de riqueza e propriedades é um fator importante de diferenciação social, todavia ela não é suficiente para alcançar prestígio.

Os componentes da classe superior têm que patentear, aos olhos da sociedade, seu distanciamento com relação às atividades produtivas. Esta manobra ocorre justamente nas atividades consideradas de lazer: ocupações não-industriais (ligadas à proeza), política, espetáculo, guerra, domínio das boas maneiras, domínio de línguas e outros hábitos que possam atestar que o indivíduo dispensa tempo e dinheiro aprimorando suas habilidades em ocupações que são consideradas dignas, na medida em que resultam em utilidade para o agente, como o aumento do conforto físico que o consumo de bens proporciona. ${ }^{2}$

Portanto, o consumo para Veblen (1974) apresenta duas hipóteses: a) atendimento tanto das necessidades físicas do consumidor (conforto material) como das suas necessidades espirituais, estéticas e intelectuais; b) ocorre devido à emulação. A posse da riqueza (propriedade) confere honra. Na sociedade industrial, os hábitos dos seres humanos convergem para a acumulação de bens, que seria sinônimo de sucesso. Isso modifica o hábito de pensar, ou seja, no lugar das façanhas predatórias entra o ato de acumular. Aquilo que é consumido pode ser considerado como supérfluo, mas depois são incorporados para dar prestígio, isto é, mudança psicológica que passa a proporcionar bem-estar espiritual. Isso significa que consumir determinados objetos ou ter certos hábitos passa a obedecer a uma certa ordem moral, ou seja, há uma finalidade em consumir mais e mais.

O padrão de vida é dado pelo consumo ideal. O motivo é a competição, pois o estímulo é a comparação individual, que nos

\footnotetext{
$2 \mathrm{Em}$ comparação com as atividades industriais, consideradas rotineiras: o trabalho na indústria, o esforço para criar e transformar a matéria passiva e bruta, isto é, todo ato que não envolva proeza é considerado indigno. Cabe ressaltar que para Veblen tal discriminação entre proeza e trabalho rotineiro é ofensiva e injusta. Entretanto, cabe a ele entender
} a sociedade como ela é, e não como ele deseja que esta venha a ser.

Movimento, Porto Alegre, v.12, n. 02, p. 241-271, maio/agosto de 2006. 
instiga a superar aqueles que pertencem à nossa classe. Já o padrão de decência é dado pelo hábito que vigora entre a classe logo acima. Em última instância, a classe ociosa dita a regra do respeito, ou pelo menos o que dá respeito (é a valorização do TER em relação ao SER, no caso da sociedade moderna). Esses padrões são formulados de uma forma muito lenta, moldando os usos e as atitudes das classes inferiores.

O padrão de vida é por sua natureza um hábito. O consumo não é determinado pelo código genético. Mas os costumes mais antigos são os mais arraigados e persistentes. Esses hábitos podem se tornar os primeiros numa escala de valores, isto é, as exigências mais baixas ou mais elementares. Um exemplo cotidiano seria o pão e leite versus o cigarro.

Quais são as variáveis para manter ou adquirir novos hábitos? Tendências e características de temperamento valem tanto quanto o tempo em que determinado hábito se repete. Os homens apresentam alguns hábitos coincidentes, e estes podem causar grande influência sobre o bem-estar. Mas o desempenho recai sobre a competição e a comparação individual. Isso equivale a dizer que, em qualquer comunidade onde os gastos conspícuos constituam uma parte do esquema de vida, um aumento na capacidade individual de gastar se canalizará provavelmente num sentido já consagrado do consumo conspícuo. Nas sociedades industriais isso se exprime pela expressão de alguma forma de desperdício conspícuo. Supridas as necessidades básicas da vida, o ser humano se rivaliza pelo acúmulo de bens. Assim como a propriedade se torna a base convencional da estima social, isto é, nenhuma posição honrosa na comunidade é possível sem ela. Em síntese: a posição social se estabelece pela riqueza e um certo padrão de proeza.

Ter lazer é um sinal de riqueza. Por meio dele (consumo conspícuo), é possível obter respeito e demonstrar força pecuniária e força superior. Mostra que a classe ociosa pode despender tempo para tal atividade, e esta não se constituir em trabalho. Isso se

Movimento, Porto Alegre, v.12, n. 02, p. 241-271, maio/agosto de 2006. 
torna um hábito mental associado a honra e nobreza. O consumo conspícuo significa que o consumo de qualquer bem serve basicamente para manter o prestígio social, o status. Dessa forma, para Veblen (1974) as pessoas efetivamente se ocupam e se preocupam com a exibição conspícua de lazer.

Outra forma de perceber o consumo é por meio dos trabalhos de Adorno e Horkheimer (1986), autores da Escola de Frankfurt. Inicialmente apresentamos sumariamente alguns conceitos desses autores. A Escola de Frankfurt, ao tratar da categoria indústria cultural, estabeleceu relações entre produção material e produção simbólica, para posteriormente refletir sobre as formas como são estabelecidas culturalmente. Para tanto, alguns termos serão brevemente discutidos, dos quais destacamos produção de bens culturais, cultura, massa, indústria cultural.

Passamos a apresentar a discussão teórica elaborada pelos autores sobre o conceito de produção de bens culturais. Uma das características da sociedade moderna é de ter possibilitado o contato de milhões de pessoas com o que se produz culturalmente. Mas o acesso nesse caso significa que tipo de participação? Como esses bens culturais são produzidos, e de que forma se inserem na sociedade? Antes mesmo de buscar respostas a estes questionamentos, outro se faz prioritário: a cultura que emerge é produzida pela massa? Adorno e Horkheimer (1986, p. 114) em Dialética do esclarecimento, nas páginas iniciais do item "A indústria cultural: o esclarecimento como mitificação das massas", afirmam que "sob o poder do monopólio, toda cultura de massa é idêntica, e seu esqueleto, a ossatura conceitual fabricada por aquele começa a se delinear [...]. A verdade é que não passam de um negócio, eles a utilizam como uma ideologia destinada a legitimar o lixo que propositalmente produzem." Diante disso, os bens culturais com os quais as massas entram em contato advêm da subsunção do valor de uso de troca das mercadorias, submetendose às regras da mercantilização e da industrialização.

Movimento, Porto Alegre, v.12, n. 02, p. 241-271, maio/agosto de 2006. 
A produção e a reprodução da cultura obedecem à mesma lógica da construção de qualquer outro tipo de mercadoria. Assim, Adorno e Horkheimer não utilizam a expressão cultura de massas, substituindo-a por indústria cultural. No ponto de vista dos autores, o conceito de indústria cultural está relacionado ao processo de mercantilização da cultura na sociedade capitalista. Já a terminologia cultura de massas carrega consigo a idéia dos costumes que surgem espontaneamente no interior das massas, falseando a clarificação do significado utilizado atualmente do termo cultura, que emerge pautado na racionalidade técnica, na mecanização da produção dos bens culturais: dade mais justa depende do estranhamento da subjetividade em relação ao mundo fenomênico $e \quad d a$ sua conseqüente objetivação $e$ reapropriação, fornecendo as bases estruturais da cultura. Deve-se, no entanto, estar alerta tanto para a tendência de negação das condicões sociais que determinaram sua produção, como para a outra face da moeda que diz respeito à tentativa de compreender a cultura como mera configuração da realidade, como mera adaptação. Ambas as situações acabam por convergir naquilo que Adorno chamou de semicultura, ou seja, a difusão de uma produção simbólica onde predomina a dimensão instrumental voltada para a adaptação e o conformismo, subjugando a dimensão emancipatória que se encontra "travada", porém não desaparecida (ADORNO; HORKHEIMER, 1986, p. 58).

A produção cultural é falsamente democratizada. A possibilidade de sobrevivência da cultura está na probabilidade de se restabelecer a sua função crítica. O fato de se acreditar que a massificação por si só garante o fim das desigualdades entre grupos sociais é um tanto perigoso, e no mínimo ingênuo.

Isso pode ser muito bem observado se retrocedermos historicamente, ao tempo em que a cultura não tinha ainda adquirido o

Movimento, Porto Alegre, v.12, n. 02, p. 241-271, maio/agosto de 2006. 
valor de troca. As facilidades de poder contemplar ou participar dessas modalidades esportivas e de lazer ao final do século XX não significa democracia, espontaneidade ou felicidade. Para Adorno, "[...] a diversão é o prolongamento do trabalho no capitalismo tardio. Ela é procurada por quem quer escapar ao processo de trabalho mecanizado para se pôr de novo em condições de enfrentá-lo" (ADORNO; HORKHEIMER, 1986, p. 61-62).

Ao mesmo tempo em que a produção cultural segue a racionalidade da indústria (privilegiando a técnica, o ritmo de produção, a divisão de tarefas, os aspectos burocráticos, o valor de troca dado à "mercadoria cultural"), paralelamente é capaz de se adaptar, principalmente em virtude da flexibilidade do sistema capitalista de produção em absorver, em sua lógica, quaisquer tipos de valores e comportamentos, que poderiam estar em contradição com seus princípios gerais.

Como conseqüência, a produção simbólica não é apenas indústria - como seria mais fácil de se supor, seguindo o modelo da racionalidade técnica - e nem só cultura, pois a sua produção está em consonância com as leis do mercado, que a identificam com características particulares.

A cultura moderna aplica a tudo uma aparência de semelhança, trazendo consigo a sensação de que cada indivíduo é um ser autônomo, que pode fazer valer sua própria vontade. E cada vez mais essa idéia é coesa no interior da sociedade. Quando um grande número de pessoas participa da compra de um mesmo produto ou da possibilidade de apreciar determinados espetáculos artísticos, esses acontecimentos são enaltecidos por aqueles que defendem a indústria cultural, cuja base de explicação baseia-se na tecnologia: "[...] o fato de que milhões de pessoas participam dessa indústria imporia métodos de reprodução que, por sua vez, tornam inevitável a disseminação de bens padronizados para a satisfação de necessidades iguais [...]. Os padrões teriam resultado originariamente das necessidades dos consumidores: eis por

Movimento, Porto Alegre, v.12, n. 02, p. 241-271, maio/agosto de 2006. 
que são aceitos sem resistência." Na realidade, o que não se explicita "[...] é que o terreno no qual a técnica conquista seu poder sobre a sociedade é o poder que os economicamente mais fortes exercem sobre a sociedade. A racionalidade técnica hoje é a racionalidade da própria dominação" (ADORNO; HORKHEIMER, 1986, p. 114).

É uma questão de negócio, e os valores orçamentários da indústria cultural nada têm a ver com os valores objetivos, isto é, a cultura é consolidada e reproduzida priorizando o princípio da comercialização de seus produtos. E os homens - que agora não são mais homens no sentido lato da palavra, mas rotulados de consumidores, diferenciados por letras A, B, C, das tabelas estatísticas dos institutos de pesquisas - vivem da ilusão de que a indústria cultural proporciona a livre concorrência e a possibilidade de escolha. "A necessidade que talvez pudesse escapar ao controle central já é recalcada pelo controle da consciência individual" (ADORNO; HORKHEIMER, 1986, p. 114). A frase dos autores expõe como a sociedade vai se tornando igual através do desaparecimento das diferenças, uniformizada pelo sistema. Portanto, ocorre a desvalorização do sujeito, pois cada vez mais o indivíduo vai desaparecendo invadido pelo social. Passa-se a valorizar o coletivo, o que significa a exploração da racionalidade através da otimização do processo técnico. Isso leva Adorno e Horkheimer (1986, p. 119) a afirmar:

\footnotetext{
A violência da sociedade industrial instalouse nos homens uma vez por todas. Os produtos da indústria cultural podem ter a certeza de que até mesmo os mais distraídos vão consumi-los alertamente. Cada qual é um modelo de gigantesca maquinaria econômica que, desde o início, não dá folga a ninguém, tanto no trabalho quanto no descanso, que tanto se assemelha ao trabalho, [grifo nosso].
} 
No lazer as pessoas acabam se orientando pelo mesmo processo técnico que caracteriza a produção. Portanto, o tempo livre passa a ter a conotação contrária ao seu próprio conceito, pois nele se prolonga a submissão dos processos verificados no trabalho. Parece evidente a hipótese de que a "produção regula o consumo tanto na vida material quanto na vida espiritual, sobretudo ali onde se aproximou tanto do material como na indústria cultural" (ADORNO, 1995, p. 80). Isso significa que, mesmo onde o indivíduo está subjetivamente convicto de operar por vontade própria, essa aspiração é modelada. A indústria cultural proporciona "produtos" para o tempo livre. Estes produtos não permitem ir além do óbvio e reproduzem, através da perfeição técnica, o mundo exterior.

Conforme observa Costa (1994, p. 183):

$$
\begin{aligned}
& \text { O processo de instrumentalização do saber } \\
& \text { para o controle da natureza se volta para a } \\
& \text { repressão do homem e atinge todos os campos } \\
& \text { da vida humana e encontra na indústria cultu- } \\
& \text { ral, no lazer administrado, formas continua- } \\
& \text { das de mistificação e de alienação da realida- } \\
& \text { de. A racionalidade positiva mutila a imagi- } \\
& \text { nação e a indústria cultural, a partir de sua } \\
& \text { lógica de padronização, incorpora às técnicas } \\
& \text { e formas de mensagem as regras da produção } \\
& \text { econômica. Daí se pensar no lazer como ex- } \\
& \text { tensão do trabalho e da lógica da mercadoria } \\
& \text { que intermedia as relações sociais e a produ- } \\
& \text { ção de bens artísticos e culturais. }
\end{aligned}
$$

O tempo livre como um momento propício para a reflexão, que ofereceria condições de uma certa independência, de um certo distanciamento da própria sociedade que o produziu, não se estabelece na sociedade subordinada ao valor de troca. O uso do tempo livre se dá através da dependência aos processos industriais. Subordinando da mesma maneira o tempo de trabalho e o tempo livre, restringe a produção espiritual do homem:

Movimento, Porto Alegre, v.12, n. 02, p. 241-271, maio/agosto de 2006. 
[...] a produção capitalista os mantém tão bem presos ao corpo e alma que eles sucumbem sem resistência ao que lhes é oferecido. Assim como os dominados sempre levaram mais a sério do que os dominadores a moral que deles recebiam, hoje em dia as massas logradas sucumbem mais facilmente ao mito do sucesso do que os bemsucedidos. Elas têm os desejos deles. Obstinadamente, insistem na ideologia que as escraviza. (ADORNO; HORKHEIMER; 1986, p. 125).

Portanto, de acordo com Adorno e Horkheimer, (1986) nem em seu trabalho nem no tempo livre os indivíduos dispõem de real liberdade. Normalmente a indústria cultural não tolera o novo. $\mathrm{O}$ fato de que novas técnicas se aperfeiçoem na produção em massa não significa necessariamente aceitar o novo fora do sistema, pois aceitá-lo seria correr riscos. O que pode surgir de novo no tempo livre das pessoas tem que necessariamente se adaptar ao que determina o consumo.

Além da necessidade de adaptação, o novo não deve extrapolar a diversão. A diversão permeia toda a indústria cultural, e mantém sob controle seus consumidores através deste princípio. A diversão é a chave para se manter a idéia de negócio, de propagar o poder da indústria cultural, procurando se identificar com a necessidade produzida. Sobre diversão, o prolongamento do trabalho e a necessidade do consumidor em não ter pensamento próprio, Adorno e Horkheimer (1986, p. 128) explicam:

$$
\begin{aligned}
& \text { [...] a mecanização atingiu um tal poderio so- } \\
& \text { bre a pessoa em seu lazer e sobre a sua felici- } \\
& \text { dade, ela determina tão profundamente a fa- } \\
& \text { bricação de mercadorias destinadas à diver- } \\
& \text { são, que essa pessoa não pode mais perceber } \\
& \text { outra coisa senão as cópias que reproduzem o } \\
& \text { próprio processo de trabalho. O pretenso con- } \\
& \text { teúdo não passa de uma fachada desbotada: o } \\
& \text { que fica gravado é a seqüência automatizada } \\
& \text { de operações padronizadas. Ao processo de tra- } \\
& \text { balho na fábrica e no escritório só pode esca- }
\end{aligned}
$$

Movimento, Porto Alegre, v.12, n. 02, p. 241-271, maio/agosto de 2006. 


\begin{abstract}
par adaptando-se a ele durante o ócio. Eis aí a doença incurável de toda diversão. O prazer acaba de congelar no aborrecimento, porquanto, para continuar a ser um prazer, não deve mais exigir esforço e, por isso, tem que se mover rigorosamente nos trilhos gastos das associações habituais.
\end{abstract}

Estamos diante de uma diversão que limita a ação reflexiva, pois o pensamento é suprimido e/ou fragmentado. As informações desfilam à frente de nossos olhos na sociedade numa velocidade espantosa, absorvendo o consumidor na sua totalidade. Os momentos de reflexão são ínfimos para o consumidor que busca na diversão do consumo massificado uma vida mais humana para os homens. Mas não podemos esquecer que a capacidade técnica está a serviço da ideologia voltada para o negócio. Como negócio, não exclui qualquer possibilidade, prevalece a idéia do "tudo pode".

Todavia, o prazer e a diversão permitida pela indústria cultural não estabelece um vínculo com a vida cotidiana, pois se constituem em promessas e ilusões que não se realizam, mas que ajudam as pessoas a dominar suas emoções na vida real. A indústria cultural transforma a diversão numa grande mentira, "[...] cada espetáculo da indústria cultural vem mais uma vez aplicar e demonstrar de maneira inequívoca a renúncia permanente que a civilização impõe às pessoas. Oferecer-lhes algo e ao mesmo tempo privá-las disso é a mesma coisa" (ADORNO, HORKHEIMER, 1986, p. 132). O que se permite é a exploração dos sentimentos, do amor ao ódio, do riso ao choro. Divertir-se significa não ter o que pensar, esquecer o sofrimento até onde ele é mostrado, "é na verdade uma fuga, mas não, como afirma, uma fuga da realidade ruim, mas da última idéia de resistência que essa realidade ainda deixa subsistir" (ADORNO, HORKHEIMER, 1986, p. 135). Numa sociedade onde prevalece a relação de troca entre os indivíduos, a possibilidade de crítica é minimizada.

Concentrando-se na teoria configuracionista e em como são

Movimento, Porto Alegre, v.12, n. 02, p. 241-271, maio/agosto de 2006. 
definidas a maneiras como as pessoas se comportam com relação ao consumo, optamos em utilizar os estudos de Mike Featherstone.

De acordo Featherstone (1995), a emergência de um modelo cultural novo, a partir dos anos 50, é caracterizada pela expansão da importância da cultura nas sociedades ocidentais contemporâneas. O autor apresenta três vertentes teóricas sobre cultura de consumo. A primeira vertente tem como premissa a expansão da produção capitalista de mercadorias. Para a economia clássica, o objetivo de toda produção é o consumo. A expansão de novos mercados e a educação de novos consumidores por meio dos meios de comunicação de massa possibilita à produção capitalista produzir maiores oportunidades de consumo controlado e manipulado.

A lógica do capital explica a progressiva destruição da cultura tradicional e da alta cultura, uma vez que todas as diferenças essenciais, as tradições culturais e qualidades são transformadas em quantidades. Seria possível argumentar que é possível o cálculo instrumental racional de todos os aspectos da vida.

Para receber os produtos, a mídia e a publicidade se encarregam de educar os consumidores. Essa é uma forma para explicar a gradativa modificação ou então destruição da cultura tradicional e da alta cultura, embora encontre dificuldades para explicar as práticas e as experiências reais de consumo. De um lado, é considerado como um fenômeno que proporciona uma democratização cultural; por outro, como um fenômeno de manipulação ideológica e controle implícito da população.

A segunda vertente deriva de estudos sociológicos e ressalta o uso da mercadoria como forma de criar vínculos ou estabelecer distinções sociais. As mercadorias não carregam consigo somente o valor de produto acabado, há também um valor agregado, o valor simbólico, encarregado de enfatizar um estilo de vida, demarcando as relações sociais (o consumo conspícuo, marco da obra de Veblen, por exemplo):

Movimento, Porto Alegre, v.12, n. 02, p. 241-271, maio/agosto de 2006. 
É nesse sentido que podemos designar o as pecto "duplamente" simbólico das mercadorias nas sociedades ocidentais contemporâneas: o simbolismo não se evidencia apenas no design e no imaginário embutido nos processos de produção e marketing; as associações simbólicas das mercadorias podem ser utilizadas $e$ renegociadas para enfatizar diferenças de estilo de vida, demarcando relações sociais. (LEISS, 1995, p. 35)

Existe uma tendência nas sociedades ocidentais contemporâneas para a oferta de mercadorias em constante renovação, o que torna muito mais complexo o problema da leitura do status ou da posição hierárquica do portador das mercadorias. O tempo despedido para adquirir o conhecimento capital cultural, que capacita pessoas ou grupos de pessoas na classificação das mercadorias, torna-se essencial. Para serem consumidas as mercadorias, necessitam obviamente de um nível de renda elevado, como também de competência para julgar os bens e serviços simbólicos. Isso exige um investimento capital cultural e simbólico durante toda a vida, além de tempo investido na manutenção de atividades de consumo. Nas condições de uma oferta cada vez maior de bens simbólicos, cresce o desejo de usufruir, popularizando e tornando acessíveis a públicos cada vez maiores; isso faz com que ocorra uma eterna perseguição por novos bens simbólicos, a fim de se estabelecer uma diferenciação no estilo de vida. A cultura é corporificada, e isso não se refere somente à identificação de quais mercadorias estão sendo usadas, mas também de como são usadas.

A terceira vertente envolve os prazeres emocionais do consumo, os desejos e sonhos do imaginário cultural consumista, explorando a idéia de que o consumo não se relaciona somente com a produção de mercadorias. Na sociedade contemporânea existe a promessa de que a disciplina e o sacrifício destinado ao trabalho apresentariam como resultado final a superação da escassez, e conseqüentemente o atendimento das necessidades e os prazeres

Movimento, Porto Alegre, v.12, n. 02, p. 241-271, maio/agosto de 2006. 
do consumo. Desse ponto de vista, o consumo é um auxiliar do trabalho e conserva os rumos da produção. Os seres humanos estariam vivendo sobre a tensão do trabalho árduo e disciplinado e a exploração emocional do consumo. Seria como se durante o dia os homens mantivessem os valores pequeno-burgueses antigos ou tradicionais, e durante a noite assumissem a postura do homem rico e ocioso, que geralmente se entrega a uma vida social intensa.

Featherstone (1995) assinala que as pesquisas dirigidas aos deslocamentos e à transformação da noção de cultura não deveriam estar atentas à escassez, mas sim ao excesso de produtos e mercadorias. Basicamente essa vertente convida os pesquisadores a pensar em contraposição às teorias inspiradas nas noções de racionalização, mercantilização e modernização da cultura. No interior desse convite, Featherstone (1995) coloca em evidência um novo ângulo de entendimento, que está centralizado no desfrutar desse excedente, espaço tradicionalmente caracterizado pela possibilidade de ocorrência de transgressões e protestos:

\begin{abstract}
A tradição popular dos carnavais, feiras e festivais proporcionava inversões e transgressões simbólicas da cultura "civilizada" oficial e estimulava a agitação, as emoções descontroladas e os prazeres físicos grotescos, diretos e vulgares da comida farta, da bebida embriagante $e$ da promiscuidade sexual. Esses eram espaços "liminares", onde o mundo era posto de cabeca para baixo, os tabus e as fantasias eram permitidos, sonhos impossiveis poderiam se realizar (LEISS, 1995, p. 42-43).
\end{abstract}

Vários locais podem ser tomados como lugares que proporcionaram um duplo papel: lugar de expor a mercadoria e lugar de diversão. As feiras livres, as lojas de departamento ou os parques temáticos se constituíram em espaços de desordem ordenada, que reelaboraram os controles emocionais frente a uma nova forma de viver. É preciso disciplina e controle para transitar nos lugares que

Movimento, Porto Alegre, v.12, n. 02, p. 241-271, maio/agosto de 2006. 
expõe as mercadorias, contemplar, olhar e não agarrar, aproximar-se das pessoas sem se sentir ameaçado. As mercadorias e as imagens podem evocar perturbações, desejos e prazeres, mas é necessário manter o autocontrole. Assim os seres humanos aprenderam a controlar mais facilmente as oscilações entre a ordem e a desordem, a consciência do real e a fantasia. Em suma, a forma de se movimentar nestes locais requer um alto grau de controle das emoções.

Para Featherstone (1995), a cultura de consumo da atualidade parece estar ampliando as situações e os contextos em que os comportamentos são aceitáveis, pois as pessoas cada vez mais adotam uma postura aberta às formas de expressão emocional:

$$
\begin{aligned}
& \text { A cultura de consumo da atualidade não re- } \\
& \text { presenta nem um lapso do controle, nem a ins- } \\
& \text { tituição de controles mais rígidos; mas, an- } \\
& \text { tes, a corroboração dos controles por uma es- } \\
& \text { trutura gerativa subjacente flexível, capaz de } \\
& \text { lidar ao mesmo tempo com o controle formal } \\
& \text { e o descontrole, bem como facilitar uma troca } \\
& \text { de marchas confortável entre ambos. } \\
& \text { (FEATHERSTONE, 1995, p. 48) }
\end{aligned}
$$

Portanto, na sociedade contemporânea, existe menos interesse em construir um estilo coerente do que em expandir a série de estilos já conhecidos, como alta cultura e cultura popular, e jogar com essas possibilidades. Na tentativa de compreender a dimensão cultural cotidiana, há algo bastante complexo por sua própria natureza: temos que investigar como se dá o relacionamento entre a produção e circulação das teorias e a produção e circulação mais ampla das experiências culturais cotidianas. Em suma, temos que explicar dois aspectos: o teórico e o cotidiano, abrangendo as mudanças na produção, no consumo e na circulação de bens e práticas culturais.

Movimento, Porto Alegre, v.12, n. 02, p. 241-271, maio/agosto de 2006. 


\section{Entrevistas}

O caminho percorrido para a obtenção dos dados foi a pesquisa exploratória. A utilização desse tipo de pesquisa, caracterizada por apresentar uma menor rigidez no planejamento, justificase nesse caso: a) pelo tempo restrito entre a confirmação do convênio entre a Universidade Federal do Paraná e a Paraná Esporte, e a execução do projeto "Viva o Verão"; e b) no início do ano de 2005, tínhamos como objetivo de proporcionar uma visão geral sobre a formulação dos hábitos de esporte e lazer, pois o tema é bastante genérico e a delimitação dos procedimentos careciam de um projeto que denominamos de "piloto-exploratório". Os dados coletados por essa pesquisa exploratória constituíram a primeira etapa de uma investigação que se pretende mais ampla - que no momento apresenta uma preocupação metodológica mais refinada, levando em consideração procedimentos de amostragem e técnicas quantitativas de coletas de dados - e foi de extrema valia no caminho a ser estabelecido.

Neste texto, estamos tratando dessas entrevistas exploratórias realizadas durante o mês de janeiro de 2005, no litoral paranaense, por mais de 03 bolsistas estudantes de Educação Física. Todos foram treinados para esta tarefa, com simulações feitas no Departamento de Educação Física da Universidade Federal do Paraná, por meio professoras e professores voluntários. As entrevistas foram elaboradas de forma semi-estruturada, isto é, a maioria das perguntas apresenta uma alternativa para a resposta, sendo que em 6 das demais perguntas os entrevistados poderiam se manifestar por meio de questões abertas. O número total de questões foi de 17 . Foram entrevistadas 24 pessoas, mantendo a proporcionalidade entre os gêneros. Basicamente, as perguntas abordaram as atividades rotineiras; as atividades semi-rotineiras, que podem abrigar atividades com certo grau de interesse próprio; e as atividades que normalmente se distanciam das atividades ordinárias e podem provocar o riso e o choro, a alegria

Movimento, Porto Alegre, v.12, n. 02, p. 241-271, maio/agosto de 2006. 
e a tristeza, o medo e o prazer. Também procuramos detectar as barreiras que impedem a participação no esporte e no lazer. Na análise das questões utilizamos dessas três categorias (rotineiras, semi-rotineiras e recreativas) (ELIAS, 1986). ${ }^{3}$ Portanto, a opção para a análise foi por meio de categorias pré-estabelecidas. A análise poderia ocorrer através do campo, mas como parte de uma pesquisa exploratória, buscamos a teoria de Elias para dar sustentação na analise das questões.

A faixa etária abordada pelas pesquisas corresponde ao período de passagem da adolescência para a vida adulta (de 18 a 30 anos), na qual a maioria das pessoas já tem alguma preocupação com o seu sustento. Não é uma passagem abrupta, mas gradativamente as atividades rotineiras se tornam mais marcantes com relação ao tempo dedicado à família, aos estudos e ao trabalho. Todavia, há indícios de que as experiências no lazer se tornem mais ativas.

A idade cronológica não é, por si só, um componente suficiente para explicar todas as diferenças. Outros fatores, como sexo, estado civil e filhos, são apresentados como elementos que podem influenciar as atividades de lazer. Vamos agora à interpretação dos dados.

Os homens não têm o hábito de auxiliar nos afazeres da casa, embora existe a propensão de realizarem essas tarefas esporadicamente. Em contraposição, as mulheres nessa faixa etária auxiliam normalmente nos afazeres domésticos, mesmo aquelas que têm uma rotina diária de mais de 8 horas de trabalho. Há um grupo de mulheres que apresentam uma carga horária de trabalho elevada, mas mesmo assim dedicam parte do seu tempo livre dos fins de semana para os afazeres domésticos. Isso independente da renda familiar. ${ }^{3}$ No capítulo 2 os autores apresentam uma tipologia para o lazer, inserindo vários exem-
plos e explicando detalhadamente o que vem ser as atividades rotineiras, semi- rotineiras e as demais voltadas para a quebra da rotina.

Movimento, Porto Alegre, v.12, n. 02, p. 241-271, maio/agosto de 2006. 
As mulheres com renda familiar reduzida, se comparadas com as mulheres com renda superior, procuram participar das atividades religiosas (que podem apresentar uma escolha própria, mas também podem se transformar em atividades rotineiras), com maior frequiência no transcorrer da semana. Outro dado corriqueiro entre as mulheres é que as que apresentam maior tempo de estudo em escolas particulares são as que mais trabalham e têm renda salarial mais alta. Portanto, o investimento em educação normalmente garante maiores possibilidades de ganhos mensais, e com menor quantidade de tempo livre.

Com relação aos homens e as atividades religiosas, podemos afirmar que na maioria dos casos os mesmos não têm o hábito de frequientar os espaços relacionados a essas atividades. No caso de levarmos em consideração a participação em grupos espontaneamente, notaremos que na soma dos gêneros as atividades religiosas aparecem em segundo lugar. Elas perdem para os clubes associativos, o que demonstra que este espaço representa um ambiente importante de sociabilidade. Não podemos esquecer que as características dos clubes citados são de direito privado, cobram mensalidades, embora não apresentem como objetivo o lucro.

A amostra revelou que os homens não têm hobbies e nem o hábito de trabalhar voluntariamente. Uma parte significativa dos entrevistados freqüenta curso de graduação, estendendo seus estudos em cursos de especialização ou cursos que possibilitem investimentos técnicos pessoais. Outra parte dos entrevistados trabalha mais de 44 horas semanais e justifica que no tempo livre procuram ficar com a família, executar tarefas rotineiras no comércio local ou simplesmente se divertir.

Com relação às atividades menos rotineiras, os adultos apresentam uma forma muito variada de utilização do tempo livre. Na maioria dos casos este tempo livre se evidencia nos fins de semana e nos feriados. Nesse espaço de tempo mais prolongado, não há um destaque especial indicado pelas mulheres; é comum citarem

Movimento, Porto Alegre, v.12, n. 02, p. 241-271, maio/agosto de 2006. 
o divertimento como busca final, o namorar ou simplesmente se reunirem em pequenos grupos, nos locais mais diversificados. Há que se notar que com o matrimônio o espaço feminino e o círculo de amizades se restringem. Os espaços da casa e de familiares são os mais freqüentados. Isso permite inferir que os adultos têm mais disponibilidade de tempo para dedicar-se aos familiares e amigos. Entre os homens, destacam-se as atividades de cunho associativistas, realizadas principalmente no período vespertino e voltadas ao esporte.

Para os homens a televisão e a internet são acessadas por mais de três horas diárias cada uma, sem uma supremacia de uma sobre a outra. Essa atividade é a ocupação que consome a maior parte do tempo de lazer de ambos os sexos. Entre as mulheres, a média de tempo de acesso à internet é o dobro do tempo que estas dispensam à televisão. Esse dado é no mínimo curioso, porque popularmente a televisão associa as novelas ao público feminino. Temos que considerar que a pesquisa não distingue se as horas gastas na internet são mais relacionadas ao prazer e à diversão ou a trabalho ou formação intelectual.

Com relação às atividades menos rotineiras, entre os homens aparecem em maior freqüência, em ordem decrescente: restaurante, cinema, teatro, viagem nos feriados. Nas atividades consideradas esportivas, voleibol, surfe e basquetebol aparecem com certa frequiência, mas o futebol é o mais citado. Além disso, os jogos eletrônicos, escutar música e a caminhada são práticas comuns. Percebe-se que há maior incidência das atividades esportivas no início da faixa etária pesquisada, isto é, com o aumento da idade ocorre uma menor busca pelas atividades esportivas. $\mathrm{O}$ menor tempo para as atividades esportivas também ocorre com os casais com filhos.

Como atividades menos rotineiras, as mulheres buscam mais freqüentemente ir a restaurantes. Empatadas em segundo lugar estão atividades como dançar, caminhar e ir ao cinema; na sequiên-

Movimento, Porto Alegre, v.12, n. 02, p. 241-271, maio/agosto de 2006. 
cia, atividades físicas (que se resumem ao esporte voleibol ${ }^{4}$, à academia e à hidroginástica) e assistir filmes e escutar músicas em casa. Com menor frequiência aparecem as viagens.

Há algumas alternâncias entre os gêneros com relação à ocupação do tempo livre. As atividades culturais são as mais citadas pelas mulheres, enquanto as atividades esportivas são as mais mencionadas pelos homens. Próximo aos 30 anos ocorre um menor interesse pelas atividades esportivas. Se considerarmos os encontros sociais como atividades de lazer e entretenimento, não ocorrem variações entre os gêneros.

Essa comparação entre os homens e as mulheres acaba evidenciando, no que se refere a gênero, a tradição brasileira com relação à ocupação espacial: os homens parecem circular mais à vontade no espaço público, enquanto as mulheres estão muito mais próximas ao espaço da casa e têm menor possibilidade de praticar atividades fora do âmbito doméstico.

Os locais mais citados para o convívio social são os bares, as casas noturnas, a própria casa, as casas de amigos, os parques públicos, os clubes particulares e as praças públicas. Entre as mulheres, a falta de tempo livre é o motivo mais citado para repetição dos hábitos mais frequientes de lazer, isto é, elas anseiam em aprofundar seus estudos, praticar esportes, ir com maior frequiência a programas culturais, mas lhes falta tempo para essas atividades.

Com relação aos projetos culturais elaborados por algum órgão governamental, a grande maioria aponta que não participaram desse tipo de programa nos últimos anos. Todavia, citam que na adolescência e na juventude participaram de muitos projetos de esporte e lazer. Entre eles os mais citados foram os jogos escolares, os Jogos da Juventude, os Jogos Regionais e os Jogos Abertos

${ }^{4}$ Há certa coerência com relação aos esportes, porque na adolescência o voleibol é o mais citado por esse grupo.

Movimento, Porto Alegre, v.12, n. 02, p. 241-271, maio/agosto de 2006. 
do Interior. Projetos culturais como visitação a museus e teatros e ainda passeios aos parques fizeram parte do período que antecedeu a idade adulta, e normalmente ficaram a cargo das escolas. Com a chegada da idade adulta, há um corte profundo na importância da escola na influência de programas culturais, pois não há relatos de utilização das escolas nos fins de semana para eventos esportivos, de lazer ou culturais.

Os entrevistados que freqüentam os cursos superiores mantêm a mesma prática de não utilizar os equipamentos dos locais de estudo nos fins de semana. São raros os casos de adultos em cursos superiores que mantêm uma relação com o espaço acadêmico fora do horário de aula com a finalidade da prática de esporte e lazer. Quando este item apareceu nas respostas às entrevistas, não estava relacionado aos esportes de forma lúdica, e sim a treinamentos esporádicos de equipes ligadas aos jogos universitários ou a atividades como coral ou participação na política estudantil. Dos poucos universitários que indicaram esta participação, todos provinham de faculdades públicas.

Nesta pesquisa, que enfatiza a idade de 18 a 30 anos, notamos que há uma variedade de situações que impedem a prática das atividades lúdicas. Tanto os homens quantos as mulheres que nessa faixa etária são pais, enfatizam que a maioria do tempo livre é utilizada em função dos filhos. A grande maioria dos entrevistados afirmou que não faz tudo o que realmente deseja. Os filhos são apresentados como a terceira maior barreira para o divertimento. Nessa faixa etária, os recursos econômicos são citados como principal empecilho para a realização daquilo que as pessoas pretendem fazer. Entre as diferentes faixas de renda, não há grandes variações nesse índice.

O que chama a atenção são as diferenças nos níveis de escolaridade: adultos com escolaridade de curso superior alegam que a maior barreira para a realização do que gostariam de fazer é a falta de tempo livre e não necessariamente a falta de recursos

Movimento, Porto Alegre, v.12, n. 02, p. 241-271, maio/agosto de 2006. 
financeiros. Há uma grande frustração entre os adultos com relação ao tempo livre, pois há uma inversão daquilo que na fase da juventude eles tinham: maior número de situações de tempo livre, que concorriam com menor poder econômico e maiores restrições familiares. Agora que apresentam maior autonomia financeira e decisória, são restringidos pelo padrão racional da indústria, que muitas vezes pode influenciar as atividades não rotineiras.

Há uma diversificação muito ampla sobre os desejos que gostariam de realizar, mas com pequenas variações entre homens e mulheres. Atividades culturais, como cinema, teatro e shows musicais, formam um grande grupo; adquirir bens duráveis ligados ao divertimento, tais como aparelhos de som, televisão, DVD e computador formam um outro grupo. As viagens estão entre os desejos comentados, e os lugares são os mais diversificados possíveis. Muitos apontam para diferentes atividades esportivas que gostariam de realizar e muitas vezes comentam que a vontade de tal prática está associada à pretensão de melhorar sua qualidade de vida. ${ }^{5}$

\section{Algumas reflexões}

Veblen (1974) nos mostrou por meio de um estudo da economia a importância dos esportes e do lazer na sociedade moderna. $\mathrm{O}$ interessante é que o autor não conviveu com os grandes espetáculos esportivos do século XX: as olimpíadas modernas, as olimpíadas de inverno, os campeonatos mundiais de voleibol, basquetebol, natação e, sobretudo, com as copas do mundo futebol. Também não conhecia os grandes parques temáticos, os esportes de aventura e o fato de o tempo livre ter sido abarcado pela indústria cultural.

Nossa hipótese é a de que Veblen,(1974) por não conhecer todo esse desenrolar do século das mudanças, pode nos mostrar o

1 O capítulo de BRENNER; DAYRELL; CARRANO em ABRAMO (2005) há um trabalho minucioso sobre a juventude brasileira e parte desse trabalho refere-se à ocupação do tempo livre.

Movimento, Porto Alegre, v.12, n. 02, p. 241-271, maio/agosto de 2006. 
significado, a difusão, a formação dos hábitos de consumo e a importância do ócio. Isso sem esquecer que as críticas ao autor têm suas limitações com relação ao tempo-espaço e à área de formação.

Veblen (1974) apresenta a idéia de que algumas mudanças psicológicas ocorreram gradativamente durante muitos séculos. A sociedade moderna está alicerçada no princípio da propriedade, que por si só não confere honra. Há necessidade de demonstrar tal riqueza perante os demais. Se em fases anteriores a proeza era o componente que dava honra, agora temos a rivalização por meio do consumo, completada pela própria proeza e façanha. Veblen (1974) ressalta a falsa individualidade e indica que muito daquilo que é constituído como hábitos de lazer é decorrente das relações de poder construídas no interior de processos culturais.

A análise das entrevistas nos mostra em parte o pensamento de Veblen (1974): a resistência (principalmente do sexo masculino) ao trabalho rotineiro e que, conseqüentemente, não confere honra; o aprimoramento dos estudos, que pode significar necessidade intelectual e de sobrevivência, um modo de conferir honra; as façanhas no esporte, que podem ser consideradas supérfluas, mas que com o passar do tempo podem indicar prestígio.

As tarefas mais rotineiras parecem estar mais confinadas ao gênero feminino. Portanto, os costumes mais antigos são os mais arraigados e persistentes, confirmando a teoria Veblen (1974). Sabemos que as mulheres na sociedade contemporânea têm assumido inúmeras tarefas, muitas até mesmo, concorrendo com o sexo masculino. Um exemplo que pode confirmar os estudos de Veblen (1974): nas entrevistas foi possível constatar que apenas um terço das mulheres apresentaram um tempo mais longo destinado a educação que leve ao aprimoramento dos estudos, e conseqüentemente ganhos mensais mais elevados. Isso faz com que essa parcela menor do gênero feminino entre em disputa com o gênero masculino no espaço do mundo do trabalho. Por outro lado, o poder de consumo delas se torna elevado. A competição entre os gêneros se

Movimento, Porto Alegre, v.12, n. 02, p. 241-271, maio/agosto de 2006. 
torna mais acirrada, pois não é só no local de trabalho, mas é a valorização do TER em relação ao SER, isto é, a mulher pode também patentear aos olhos da sociedade sua honra, ao demonstrar que consegue participar do consumo.

Por sua vez, Adorno e Horkheimer (1986) avançam significativamente na construção conceitual iniciada por Veblen (1974):

Ao enfocar a indústria cultural que, preliminarmente é definida como um sistema uniforme no todo e nas partes, é um sistema universal, controlando o esporte e o lazer especialmente quando estes são mercantilizados, e induzindo à obediência em massa de maneira não crítica, tudo se torna cada vez mais o mesmo.

O conceito de indústria cultural é realçado aqui no sentido de aprofundar o entendimento das relações de poder no contexto da sociedade capitalista, a importância dos teóricos críticos na ênfase desta problemática é indiscutível e relevante (GEBARA, 2002).

O que é discutível, inclusive gerando posições divergentes entre os teóricos críticos, são as conclusões decorrentes dessa formulação. O primeiro ponto a ser discutido é a afirmação de que as atividades de esporte e lazer reproduzem fielmente as estruturas de poder da sociedade capitalista. Outro ponto é a afirmação de que o consumo do lazer ocorre de acordo com os preceitos da indústria. Estamos diante de situações no mínimo discutíveis. A terceira afirmação a ser debatida seria a negação do consumo:

\begin{abstract}
Não somos mais uma sociedade capitalista que se explica apenas pela produção e circulação de mercadorias; Veblen já no século passado indicava a natureza desta problemática. $O$ consumo, neste século, é central para a compreensão de inúmeros fenômenos, especialmente relativo aos espetáculos esportivos e aos estilos de vida (GEBARA, 2002).
\end{abstract}

Para os frankfurtianos Horkheimer (1973) e Adorno (1995), a 
lógica da mercadoria e da racionalidade instrumental ligada à produção é percebida na esfera do consumo. $\mathrm{O}$ esporte, o lazer e a cultura, de uma forma geral, são filtrados pela indústria cultural, sendo a recepção ditada pelo valor de troca, à medida que os valores e propósitos mais elevados da cultura submetem-se à lógica do processo de produção e de mercado, o que resulta na busca mais incessante por lazer e atividades de consumo. Entretanto, as tendências emergentes não podem ser única e exclusivamente estudadas por meio da avaliação negativa dos prazeres do consumo.

Portanto, se por um lado a sociologia na sociedade contemporânea está associada ao pano de fundo da ascensão do racionalismo, que compreendeu a cultura principalmente como um reflexo do capitalismo ou da indústria, por outro lado há tentativas de compreender a dimensão cultural cotidiana, ao investigar como se dá o relacionamento entre a produção e a circulação das teorias e a produção e circulação mais ampla das experiências culturais cotidianas. Em suma, temos que explicar dois aspectos: o teórico e o cotidiano, abrangendo as mudanças na produção, no consumo e na circulação de bens e práticas culturais. Os dados quantitativos são reveladores com relação ao que pensamos da sociedade ou em relação ao que gostaríamos que ela realmente se tornasse.

A sugestão é que a sociedade deveria ser compreendida em termos de processos em curso no âmbito da dinâmica das relações entre grupos de pessoas. Isso suscita uma pergunta: quem são os produtores e os transmissores dos bens simbólicos da atualidade? As entrevistas apontam para os programas de televisão e a internet como grandes transmissores dos bens simbólicos.

Como a população paranaense adquiriu seus hábitos de lazer? Como determinados consumos são engendrados nessa população? O objetivo é ter algumas pistas e sinais, e caminhar para um mapeamento que poderá ajudar a formular as políticas públicas, o que poderá possibilitar a otimização dos recursos humanos e materiais.

Movimento, Porto Alegre, v.12, n. 02, p. 241-271, maio/agosto de 2006. 
A pesquisa apresenta o desinteresse do gênero feminino pelos esportes quando estão próximas dos trinta anos. Como fica a valorização do TER (esporte e lazer) em relação ao SER? (no sentido de que as atividades lúdico-esportivas são uma necessidade vital, e propiciam a possibilidade de sentir emoções que normalmente foram sublimadas no cotidiano). Entra aqui o questionamento para os gestores públicos de esporte e lazer: qual parcela da população está sendo atendida nos eventos de maior porte, tal como os Jogos Abertos do Interior? Qual a relação custo benefício ao realizar eventos dessa natureza para a população adulta? Ou talvez uma pergunta anterior deva ser formulada: quais devem ser as nuanças de uma política democrática para o esporte e lazer?

Por meio dos estudos de Featherstone, a década de 50 é caracterizada pela expansão da importância da cultura nas sociedades ocidentais contemporâneas. Sendo a cultura por vezes associada ao consumo e ligada ao excesso de produtos e mercadorias. Isso é uma característica marcante da sociedade contemporânea: o Ter é uma necessidade vital de sobrevivência, perante as condições de sublimação imposta pelo cotidiano.

Veblen (1974) já apontava que os hábitos mais antigos e arraigados se tornam difíceis de serem substituídos, as velhas formas de formular e operacionalizar as políticas públicas pode estar em risco. Está mais que na hora dos gestores públicos dedicarem parte do seu tempo em conhecer os hábitos da população e promover uma mudança no sentido da convergência da participação. Para tanto, a contribuição da universidade pode ser no sentido de coletar, sistematizar os dados e de interpretá-los. Esse passo está sendo dado, no sentido que esta pesquisa exploratória nos ajudou a formular novos procedimentos - definição pela pesquisa quantitativa, metodologia de aplicação, formulação do questionário para se conhecer os hábitos de esporte lazer. 
Consumption and formation of the sport habits and leisure

Abstract: Parte superior do formulário

The objective of the text is to initiate an analysis of the sport habits and leisure of the population of the city of Curitiba. The data had been collected during the project "Live the Summer" of the Government of the State of the Paraná. The procedure adopted was the exploration research, with the objective to provide a general vision on the subject. The data collected by means of the exploration research constitute the first stage of a ampler inquiry. In this text we go in them to restrict to the etary of 18 the 30 , that it corresponds to a moment of transistion between youth and the adult life. We analyze the following categories: etary band, familiar income, degree of schoolarity and as the individuals use its free time. We also consider the civil state, the parents, the degree of maturity of the family (if the children live together or separate of the parents) and the meaning of the sport consumptions and leisure. To guide the quarrel of habits, free time and consumption, we use the following theoretical sources: Veblen, and the concepts of conspicuous consumption, the Frankfurt' school and the concept of cultural industry e, finally, Featherstone, that uses the concepts and the consumption. We believe that this study it will be able to bring public subsidies for teachers and managers, therefore will more make possible the deepened understanding of some forms of behavior of the citizen.

Keywords: Leisure activities. Sports. Public policy. 


\section{Consumo y formación de los hábitos de depor-} te y ócio

Resumen: El objetivo del texto es empezar un análisis de los hábitos de deporte y ocio de la población de Curitiba. Los datos fueron obtenidos en la realización del proyecto "Viva el Verano" del gobierno del estado del Paraná. El procedimiento para la obtención de la información fue una investigación exploratoria, con el objetivo de ofrecer a los lectores una visión general sobre el tema. Los datos recorridos constituyen la primera etapa de una investigación más amplia. Aquí vamos restringir el análisis a la franja de edad entre los 18 y 30 años, que corresponde a un momento de transición entre la juventud y la vida adulta. A partir de los datos obtenidos hicimos el análisis sobre la franja de edad, renta familiar, grado de escolarización, renta familiar, nivel de escolarización y cómo los individuos utilizan su tiempo libre? Hemos considerado también el estado civil, la paternidad, el grado de madurez de la familia (si los hijos viven juntos con sus padres o no) y el significado del consumo de deporte y ocio. Para la discusión de hábitos, tiempo libre y consumo utilizamos las siguientes referencias teóricas: Veblen y los conceptos de consumo conspicuo, la Escuela de Frankfurt y el concepto de industria cultural y, por último, Featherstone, que utiliza los conceptos figuracionistas y el consumo. Creemos que el estudio podrá traer subsidios para los profesores/ investigadores y gestores públicos, una vez que hará posible la comprensión más profundizada sobre las actitudes de comportamiento ciudadano.

Palabras- clave: Actividades de Ocio. Deporte. Políticas Sociales.

\section{REFERÊNCIAS}

ADORNO, T. W. Palavras e sinais: modelos críticos II. Petrópolis: Vozes, 1995.

ADORNO, T. W.; HORKHEIMER, M. Dialética do esclarecimento: fragmentos filosóficos. Tradução de Guido Antonio de Almeida. Rio de Janeiro: Zahar, 1986. 
BRENNER, A. K.; DAYRELL, J.; CARRANO, P. Culturas do lazer e do tempo livre dos jovens brasileiros. In: ABRAMO, H. W.; BRANCO, P. P. M. (Org.). Retratos da juventude brasileira: análises de uma pesquisa nacional. São Paulo: Fundação Perseu Abramo, 2005

COSTA, B. C. G. Indústria cultural: análise crítica e suas possibilidades de revelar ou ocultar a realidade In: PUCCI, B (Org ). Teoria crítica e educação: a questão da formação cultural na Escola de Frankfurt. Petrópolis: Vozes, São Carlos: EDUFISCAR, 1994.

ELIAS, Norbert: Dunning, Eric. Quest for Excitment: Sport and Leisure in the Civilizing Process. Oxford: Blackwell, 1986.

FEATHERSTONE, Mike. Cultura de consumo e pós-modernismo. Tradução de Júlio Assis Simões. São Paulo: Studio Nobel, 1995. (Coleção Cidade Aberta Série Megalópolis)

GEBARA, Ademir. Veblen, Adorno e as bicicletas. In: CONGRESSO BRASILEIRO DE HISTORIA DA EDUCAÇÃO FÍSICA, LAZER E DANÇA. 8, 2002. Ponta Grossa, PR. Coletânea.... Ponta Grossa: Universidade Estadual de ponta Grossa, 2002.

HORKHEIMER, Max. Temas básicos da sociologia. São Paulo : Cultrix, 1973.

VEBLEN, Thorstein B. A teoria da classe ociosa. In: Os pensadores. São Paulo: Abril Cultural, 1974 